ity' are concepts banned by science, they remain ineradicable from the imaging consciousness, for which every anomalous or deviant birth reasserts the equivocal nature of the human condition. Our imagination cannot help asking: angel or beast? And the reply is, neither one nor the other; but not a third one either, not a tertium quid between these two. Is it both at the same time, or alternatively first one and then the other? Perchance a hybrid, a chimera, like the Ravenna monster that Huet describes so well: angel by the wings, fish by the scales, and goat by the hoofs.

All those interested in the history of ideas, myths and symbols should welcome the appearance of these two books. Both show that only the imagination truly perceives the elusiveness of our nature. For the human element will not be captured whole in the normal state or in the extremes of deviancy. At any level at which one approaches it, human nature seems to be passing through: "not always going," wrote Pascal, "but with comings and goings" (Pensées II, 27-354).

Frank Gonzalez-Crussi is in the Department of Pathology, Children's Memorial Hospital, Chicago, Illinois 60614, USA.

\title{
Biological thought in development
}

\section{Jack Cohen}

Life Cycles: Reflections of an Evol-
utionary Biologist. By John Tyler
Bonner. Princeton University Press:
1993. Pp. 209. $\$ 19.95$, £14.

NEARLY all working scientists spend their time and effort asking the next 'how?' question. On the rare occasions when they can step back from their work - from the new grant application, research report, student admission form, time sheet and so on - they can attempt to see their work in context, to ask the big 'why?' questions. Most of us don't get a chance to do this until we retire, and then much of the motive has been lost. A few biologists have managed to maintain the large view throughout their working lives, and have even written about their perspectives in books and reviews for the rest of us.

This feat seems to require an unusual combination of luck and skill from the outset. The luck comes from finding an organism with a peculiar habit, morphology or physiology: the giant nerve fibre in the cuttlefish, the peculiar mating habits of the stickleback, the geometry of the posterior clamp of monogenean fish parasites - all have launched new schools of investigation and illuminated biology more widely than might have been thought. Most biologists, however, begin with animals that sit square in the middle of our classificatory systems: ordinary mammals such as the rat; fish such as trout; and protozoa such as paramecium, easy to keep, and cheap too. Any special trick that these creatures use has unfortunately already been worked out.

John Tyler Bonner, by contrast, started with cellular slime moulds, whose disgusting name hides beautifully perverse organisms that totter on the edge of several biological assumptions. They are not unicellular, multicellular or cellular: individual amoebae live in the soil (or on a bacterial lawn on an agar plate). When they get hungry they group together, demonstrating their allegiance to secondmessenger theories of cell biology by emitting pulses of cyclic AMP as an attractant. The aggregate forms a 'slug' that creeps about, its cells differentiating into pre-stalk and pre-spore lineages in preparation for some acrobatics that bring the spore mass to the top of a long vertical anchored stalk.

Bonner observed the rest of the animal kingdom from this little offshore island of slime moulds, a position that gave him a

\section{IMAGE UNAVAILABLE FOR COPYRIGHT REASONS}

Spore tower of the slime mould Dictyostelium discoideum (SEM, $\times \sim 150$ ).

telescopic perspective on all other organisms - from there, there isn't much parallax between cuttlefish and mammals. He could see new questions ("Why reduce down to one cell to cross generations?") that led to great truths about life cycles, and about reproduction generally. $\mathrm{He}$ tackled the evolution of complexity in animals, the evolution of culture, the nature of individuality.

Now emeritus professor at Princeton University, Bonner has documented his intellectual journey among the large biological questions. He describes his progression from the initial choosing of slime moulds, through some cogitations on size, generation time, Volvox and life cycles to questions of multicellularity. Then he tackles the big question of development, that great invention so alien to the bacterium or the amoeba, which simply grow, divide, grow, divide. Development of the egg leads to a different organism, the embryo; and this in turn develops through a variety of forms to the breeding stage, which again produces - not more of itself, but eggs. We are so familiar with this that we don't see it as strange; it takes the slimemould perspective to see that the ability to become larger by developing is not just 'usual', it is also special and remarkable.

We hear about Bonner's working for E. G. Conklin one summer, when they discussed Hans Driesch, and about the great embryologists E. B. Wilson and Conrad Waddington. An account of what Bonner calls "gene nets", which have also been called co-adapted gene complexes and whose results include canalization, comes at the end of a brief paean to DNA, today mandatory in any biology book. Here too is the story of how he was scolded by Haldane for making jokes in a lecture in England (a lesson I never learned, to the dismay of my colleagues). There are asides about many other people, about progress in evolution, and about the Baldwin effect: selection for potential, for the ability to develop a character instead of selection for an overt developmental trait. Unfortunately, he chooses a fantastic example - tameness genes - instead of a real one. There are chapters on getting larger during evolution, on becoming aware and on becoming social. The last, short chapter is about the passage of culture across the generations, about bowerbirds and bluetits, and about writing and computers.

This is a relaxed book, a quiet informative series of chats from the veteran professor who's been there, done that, thought it would be interesting to have a look at one particular thing, discovered another. Perhaps this way of life can survive only in the few old universities content to maintain the ancient traditions of scholarship while the rest of us are reducing everything to job security and the quick buck and losing our academic cultural roots. When we read this book, we can pretend that we have the calm thoughts, the vast knowledge and the discipline of thought that enable Bonner to ask, and to answer, big questions in biology. Then we can go back to the grant application.

Jack Cohen is in the Ecosystem Analysis and Management Group, University of Warwick, Coventry CV4 7AL, UK.

NATURE · VOL 365 - 30 SEPTEMBER 1993 